\title{
Análise qualitativa de aspectos influentes em situações de risco observadas no gerador de vapor de uma planta petroquímica
}

\author{
Aline Fernanda de Oliveiraa, Miguel Afonso Sellittob,* \\ aalinefernandade@hotmail.com, UNISINOS, Brasil \\ b,*sellitto@unisinos.br, UNISINOS, Brasil
}

\begin{abstract}
Resumo
0 objetivo deste artigo foi apresentar uma análise de fatores que tiveram influência em situações de emergência em um gerador de vapor de uma planta petroquímica. Os objetivos secundários foram: entender e contextualizar a situação do gerador estudado; estruturar as condições em que foram observadas anormalidades no gerador; entender como essas condições afetam a segurança da operação; e propor linhas de ação para aumentá-la. 0 método de pesquisa foi o estudo de caso, com procedimento qualitativo. A principal técnica de pesquisa foram sessões de grupo focado com operadores, cujo fio condutor foi um questionário estruturado em quatro construtos: confiabilidade humana, alarmes, registros de ocorrências e capacitação. 0 resultado de pesquisa foram quatro linhas de ação sugeridas para aumentar a segurança da instalação, principalmente a confiabilidade humana: racionalização e automação de procedimentos, reprojeto de alarmes, reprojeto do sistema de informações históricas e laboratório de simulação operacional.
\end{abstract}

Palavras-chave

Erro humano. Situação de emergência. Confiabilidade humana. Interação homem-máquina.

\section{Introdução}

0 ambiente de trabalho, muitas vezes, é o lugar onde se passa grande parte do tempo desperto. Interessa torná-lo mais seguro, produtivo e agradável. Uma das causas da má qualidade de vida, perdas de produção e acidentes no local de trabalho são os erros humanos. É objetivo de programas de aumento de bem-estar e segurança no ambiente de trabalho reduzir sua frequência e a severidade de suas consequências. Para tal, um meio é a eliminação de situações percebidas como de risco nos locais de trabalho. Tal percepção é construída por fatores objetivos, tais como condições materiais e experiência de operadores; e subjetivos, tais como a confiabilidade das decisões de operadores (FISCHER; GUIMARÃES; SCHAEFFER, 2002), o que remete ao estudo das falhas humanas em situações intrinsecamente seguras, ou seja, ao estudo da confiabilidade humana (MOSLEH; CHANG, 2004; GERTMAN, 1993).
Falhas humanas podem ser ativas ou latentes, voluntárias ou involuntárias. Falhas ativas ocorrem no contexto do acidente - são as causas imediatas que determinaram a ocorrência: atos inseguros ou erros na operação de equipamentos ou dispositivos de segurança. Falhas latentes são anteriores ao acidente - atos que criaram condições para a ocorrência, tais como decisões erradas ou modelo incompleto de gestão da atividade. Falhas voluntárias são burlas intencionais de procedimentos. E falhas involuntárias são induzidas por outras falhas, tais como instrumentação descalibrada ou eventos perturbadores imprevistos (DUARTE, 2002; 0IT, 2002). Muitas vezes, falhas humanas envolvem funcionários habilidosos, produtivos e bem-intencionados: incapacidade não explica todas as anormalidades (DUARTE, 2002; LORENZO, 2001). 
Integrar homem e tecnologia pode ajudar a promover a segurança em atividades industriais. Para tanto, é preciso entender como ocorre a interação homem-máquina e como a variabilidade nas situações operacionais contribui para que falhas ocorram (MOSLEH; CHANG, 2004; GERTMAN, 1993; KIRWAN, 1992). Para Cacciabue (1997), em projetos de sistemas do tipo homem-máquina, como em salas de controle, a presença do operador deve ser considerada desde o início do projeto, reduzindo problemas de integração.

Salas de controle de plantas industriais integram sistemas e equipamentos, onde os operadores monitoram, controlam e intervêm no processo por interfaces gráficas e estações de trabalho. A interface integra informações, dados, controles e comandos em telas, condiciona as estratégias de realização da tarefa e é influente na segurança operacional, pois afeta o modo como operadores recebem informações e modificam parâmetros da operação. É pela interface que o operador faz contato perceptivo e cognitivo com a planta (TEIXEIRA et al., 2007).

Projeto e manutenção das instalações de um sistema interativo homem-máquina podem ser baseados em abordagem centrada na tecnologia ou no usuário (BARANAUSKAS; ROSSLER; OLIVEIRA, 1998). No primeiro caso, as decisões de projeto favorecem o uso e maximizam o desempenho da tecnologia. No segundo, os requisitos de usuários devem prevalecer nas decisões sobre a interface, e esta deve ser atendida pelos demais elementos do sistema (NORMAN; DRAPER, 1986). A participação dos usuários nas decisões sobre o sistema pode e deve ser estimulada ao longo de todo o ciclo de vida do sistema, pois as características das interações podem se modificar ao longo do tempo. A aplicação do método descrito neste artigo produziu ações que podem motivar decisões de mudança no projeto original, sendo um exemplo de como conduzir a participação de operadores usuários na concepção e modificação de um sistema interativo homemmáquina, tal como em instalações petroquímicas.

Nessas instalações, uma situação de emergência, tal como ruptura de tubulação ou vazamento, pode causar impactos econômicos, sociais e ambientais à empresa, à sociedade e às comunidades vizinhas. Vale a noção proposta por Reason (1997) de acidente organizacional, que transcende 0 acidente individual: um evento frequentemente catastrófico que envolve tecnologia complexa, tal como em plantas nucleares, aviação ou petroquímica. Também vale a noção de Perrow (1999) de acidente sistêmico, mais presente em sistemas sociotécnicos, cuja origem é a interdependência e a interação entre subsistemas de um sistema produtivo complexo. Dificilmente identifica-se uma e apenas uma causaraiz, cuja erradicação elimina completamente a chance de acidente. 0 risco surge como propriedade emergente em sistemas produtivos complexos baseados na interação homem-máquina.

0 objetivo principal deste artigo foi apresentar uma análise de fatores que estiveram presentes e influenciaram em situações de emergência no gerador de vapor de uma planta petroquímica. Os objetivos secundários foram: (i) entender e contextualizar a situação do gerador estudado; (ii) estruturar as condições influentes nas anormalidades observadas; (iii) entender como essas condições afetaram a segurança da operação; e (iv) propor linhas de ação para aumentá-la.

Algumas pesquisas foram consultadas e podem ser revistas em paralelo com essa pesquisa, pois contêm elementos ora utilizados: Swain (1990), Droguett e Menezes (2007), Carvalho, P., Vidal e Carvalho, E. (2005), Cacciabue (1997), Ambros (2005), Santos, Sisto e Martins (2006), Gandra, Ramalho e Gonçalves (2004), Hallbert et al. (2004) e Teixeira et al. (2007). 0 restante do artigo está organizado em: revisão sobre erro humano, cognição e confiabilidade humana; pesquisa e resultados; e linhas de ação sugeridas.

\section{Erro humano e cognição}

Falhas em sistemas produtivos podem ser causadas por falhas em componentes físicos ou lógicos do sistema. Elas podem conduzir a erro, que eventualmente se transforma em problema ou disfunção, em encadeamento de eventos como na Figura 1.

Um tipo de erro que pode ocasionar disfunção em sistemas produtivos é o erro humano. Embora o comportamento humano em ambiente complexo seja de difícil predição e tipificação (KIRWAN, 1992), vários autores já propuseram definições e tipificações para o comportamento humano em situação de erro. Para Hollnagel (1993), erro humano ocorre quando uma ação falha ao produzir um resultado esperado ou produz consequências não desejadas. Para Sanders e Moray (1991), erro humano é uma decisão ou comportamento que reduz ou tem potencial para reduzir a segurança ou o desempenho de um sistema. Para Reason (1990),

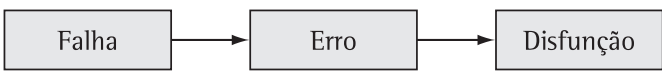

Figura 1. Encadeamento entre falha, erro e disfunção. Fonte: Almeida Jr. (2003). 
há erro humano quando uma sequência planejada de atividades falha na obtenção de um resultado e a falha não pode ser atribuída a agentes externos. Para Rasmussen (1983), se o desempenho de um sistema foi insatisfatório devido a um ato humano, esse é um erro humano. Para Kantowitz e Sorkin (1983), erro humano é uma ação que viola limites de tolerância de um sistema. Para Reason (1997), erros humanos são ações ou omissões que resultam em desvios de parâmetros e colocam pessoas, equipamentos e ambiente em risco. Uma compreensiva tipologia do erro humano é encontrada em Sharit (2006).

Reason (1990) fala em deslize, lapso e engano. Deslizes produzem comportamentos observáveis: um operador aciona a chave errada. Lapsos são erros sem comportamentos observáveis: um operador esquece de acionar uma chave. Enganos ocorrem quando há diferença entre intenção e consequência de uma tarefa: um plano mal formulado é executado sem erros. Enganos podem envolver erros de julgamento, de inferência na seleção de objetivos ou na especificação dos meios para atingi-los. Enganos podem ser por: (i) omissão, quando um passo do plano não ocorre; (ii) seleção indesejada, quando um objeto foi mal selecionado; (iii) repetição, quando um passo é repetido; ou (iv) inversão sequencial, quando um passo ocorre fora da sequência. Enganos podem ocorrer: (i) no nível de regras, quando há falha na regra de solução do problema, foi aplicada regra errada ou mal aplicada a regra certa; e (ii) no nível de conhecimento, quando surgem problemas sem regras, que serão construídas partindo de saberes prévios. Em situações de erro, operadores podem se adaptar e ser capazes de interpretar novas situações e criar definições locais para aspectos implícitos nos procedimentos (RASMUSSEN, 1983; AMALBERTI, 2003; CARVALHO, P.; VIDAL; CARVALHO, E., 2005).

Condições para a ocorrência do erro surgem quando, ao se projetar o sistema, vários fatores podem não ter sido considerados, como, por exemplo, a cultura do trabalhador e as condições do ambiente de trabalho. 0 erro humano também decorre da interação entre fatores situacionais do contexto e fatores relacionados ao indivíduo, que agem quando este tenta regular as variações do sistema e produz a variabilidade presente nos fatores subjetivos de percepção de risco (PASSOS, 2002; FISCHER; GUIMARÃES; SCHAEFFER, 2002; SANDERS, 1987).

Kantowitz e Sorkin (1983) categorizaram os principais fatores que explicam o desempenho humano e as possibilidades de erros em sistemas produtivos complexos com interação homemmáquina: (i) fatores operacionais, tais como fadiga, duração e complexidade da tarefa; (ii) fatores situacionais, tal como layout da sala e dos painéis; (iii) fatores ocupacionais, tais como atividades múltiplas e simultâneas, carga de trabalho, tipo de supervisão; (iv) fatores pessoais, tais como capacitação e experiência individual e de grupo, motivação, atitude, confiança, perda sensorial, idade, peso, altura; e (v) fatores ambientais, tais como temperatura, iluminação, espaço físico e ruído.

Um modo de entender o comportamento humano no momento do erro é entender como alguns aspectos da cognição humana estão estruturados. Para tal, lançam-se mão de modelos cognitivos que representem o processamento de informações numa tomada de decisão ou no desempenho de uma tarefa. Para Almeida (2006), na aprendizagem humana, ações inicialmente conscientes tornam-se automáticas devido à repetição. A habilidade do operador aumenta, e a tarefa passa a um nível de regulação cognitiva de menor esforço. Em situações novas ou de incerteza, volta a regulação consciente. Para Rasmussen (1983), a cognição humana pode ser: (i) baseada na habilidade, quando requer destreza sensorio-motora na tarefa, acionada automaticamente por situações rotineiras segundo um modelo mental adquirido; (ii) baseada em regras, quando segue regras construídas por aprendizagem e experiência (o sujeito interpreta a situação e elege uma regra, no espaço de solução possível); e (iii) baseada no conhecimento, quando surge uma situação nova, sem regras válidas. Comportamentos baseados em regras e em conhecimento são processos conscientes: comportamento baseado na habilidade é automático.

A Figura 2 apresenta uma representação simplificada do comportamento humano. Começa pela conscientização e percepção da situação. Depois, vem o processamento da informação e a tomada de decisão, ou seja, dentre todas as ações possiveis, qual a que será executada. Finalmente, vem a ação no mundo real e a realimentação de resultados, em ciclo fechado de aprendizagem, que pode levar a novos processos de conscientização e percepção.

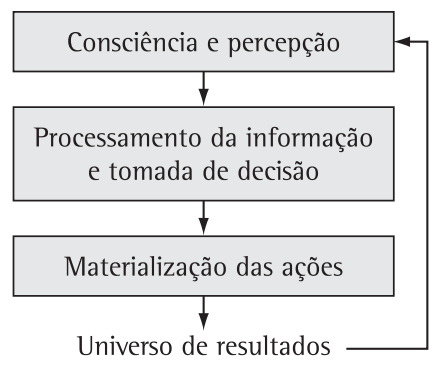

Figura 2. Modelo geral do desempenho humano. Fonte: Adaptado de Wickens (1992). 
Outro modo de representar a cognição humana é como faz Norman (1983). Para o autor, no processo de cognição humana o comportamento humano passa por sete fases de ação: formulação do objetivo; formulação da intenção; percepção do ambiente; interpretação do ambiente; definição da ação; execução da ação; e avaliação dos resultados.

Em ambos os casos, a realimentação joga importante papel, interpretando e utilizando os resultados da atividade anterior para influenciar as próximas atividades, o que é coerente com a abordagem cognitiva humana pelo modelo cibernético (ASHBY, 1956).

\section{Confiabilidade humana}

Segundo Filgueiras (1996), como disciplina formal, a confiabilidade humana teve impulso com o acidente nuclear de Three Mile-lsland. Reconheceu-se então que a ação humana, condicionada pelo ambiente e por interações sistêmicas, pode levar sistemas produtivos complexos a situações de risco.

Confiabilidade humana é a probabilidade que um operador tenha sucesso em tarefa especificada, dentro de condições e de tempo especificados, se este for limitante, sem outro resultado que degrade o sistema. Uma tarefa bem-sucedida é aquela que alcançou a meta, dentro das condições especificadas, sem criar perturbações (SWAIN; GUTMAN, 1983; LORENZO, 2001). Para Calarge e Davanso (2003), em tarefas de montagem ou de manutenção, por aprendizagem, a taxa de erros diminui e eventualmente atinge um valor constante. Para Passos (2002), o tempo aumenta a confiabilidade humana, pois trabalhadores adquirem experiência e montam esquemas antecipados de defesa contra falhas sistêmicas. Para Begosso (2005), dada a relação com o contexto e interações entre subsistemas, nem sempre dados de literatura podem ser transportados, tornando importante o registro imediato das ocorrências. Informação atrasada ou errada impõe perda de sincronia entre falha e correção. Para Guber (1998), além da probabilidade de falhas, a confiabilidade humana inclui o estudo qualitativo dos fatores que contribuem para a ocorrência da falha. Para Svedung e Rasmussen (2002), além de modelos de avaliação reativa da confiabilidade humana, é necessário considerar modelos causais sociotécnicos adaptativos, com ênfase em estratégias proativas de gerenciamento de riscos.
Cacciabue (2008), Lee, Tillman e Higgins (1988), Droguett e Menezes (2007) resenharam métodos publicados de avaliação da confiabilidade humana. Os autores distinguem métodos de primeira e segunda geração. Os de primeira se limitam a analisar as probabilidades de ocorrências de falhas; os de segunda incluem considerações sobre circunstâncias e ambiente da tarefa e admitem interdependência entre eventos.

Inserindo uma perspectiva qualitativa em estudos de confiabilidade humana, Swain e Guttmann (1983) propuseram um método para sistemas produtivos com interação homem-máquina, que consiste em: (i) descrever objetivos e funções do sistema, características situacionais e características pessoais dos operadores; (ii) descrever e analisar as tarefas para detectar situações passíveis de erro; (iii) estimar probabilidades para cada tipo de erro; (iv) determinar consequências dos erros e probabilidades de se transformar em disfunções; e (v) propor modificações para aumentar a confiabilidade do sistema. Outro método é proposto por Filgueiras (1996): (i) análise das tarefas humanas, compreendendo também o contexto físico, psicológico e organizacional; (ii) análise do erro humano, identificando situações de erro, consequências e possibilidade de recuperação; (iii) quantificação dos erros, estimando a probabilidade, a partir de dados históricos, e severidade de efeitos, por julgamento de especialistas; e (iv) propostas para evitar os erros mais críticos.

Um modo de aumentar a confiabilidade humana é o uso de procedimentos formalizados. Um procedimento consiste em uma descrição detalhada de como uma atividade deve ser realizada. Pode incluir fotografias e desenhos que auxiliem o operador a entender a tarefa e facilitem o treinamento. Também podem incorporar melhorias e correções que surgem durante a atividade, tornando-se um documento dinâmico (PULAT, 1992). Muitas vezes, procedimentos incluem tempos típicos para a atividade, que podem ser usados para verificar a adequação física e psicológica do trabalhador à atividade. 0 não atingimento desses tempos ou o decaimento ao longo do turno podem indicar inadequação laboral à tarefa (MONTMOLLIN, 1990).

Procedimentos incluem condições de trabalho e ações. Operadores atribuem-lhes valor baseado na frequência de sucesso. Quando todas as condições previstas existem, ações bem-sucedidas aumentam a confiança no procedimento. Sem condições perfeitas, operadores utilizam o procedimento mais propenso ao sucesso na condição mais parecida (BEGOSSO, 2005). Do ponto de vista 
cognitivo, a existência de procedimentos reduz o nível de complexidade da operação, diminuindo a probabilidade de erro humano, especialmente violação de rotina. Conforme esse ponto de vista, o erro humano é definido como desvio em relação à sequência de ações especificada no procedimento. Entretanto, procedimentos escritos às vezes não são seguidos à risca, pois trabalhadores podem modificar ações para se tornarem mais eficientes ao lidar com pressões temporais e demais restrições impostas por contextos de trabalho competitivos (CARVALHO, P.; VIDAL; CARVALHO, E., 2005).

Em sistemas produtivos complexos, operadores experientes podem antecipar perturbações pela capacidade adquirida de detecção e interpretação de sinais originados no sistema. Durante a atividade, operadores adquirem habilidades sensoriais e desenvolvem estratégias de raciocínio que ajudam nessa detecção e interpretação. Como a quantidade de estados possíveis é grande, operadores usam competências adquiridas por experiência para detectá-los, interpretá-los e para escolher, dentre os procedimentos existentes, qual tem mais probabilidade de sucesso. Chama-se esse processo de gestão cognitiva da atividade. 0 operador monta seu plano de ação, define objetivos e combina conteúdos cognitivos com informações sobre o sistema, contexto da tarefa e dos colegas, em singular composição de conhecimentos, crenças e confianças. Por isso, muda a percepção de risco quando muda o grupo (ALMEIDA, 2004).

\section{A pesquisa}

Como objeto de estudo, foi escolhido o gerador de vapor de uma planta petroquímica.

0 método de pesquisa foi o estudo de caso descritivo com procedimento qualitativo. Casos podem ser exploratórios, quando oferecem um primeiro contato com o objeto de pesquisa; descritivos, quando expõem características e regularidades do objeto; e explanativos, quando apontam relações causais para essas regularidades (YIN, 2001). Segundo Eckstein (1975 apud ROESCH, 2001), um estudo de caso pode dar cinco tipos de contribuição: (i) descrição aprofundada de um objeto para futuros estudos; (ii) descrição aprofundada e comparativa de regularidades presentes no objeto; (iii) verificação das regularidades por meio de uma situação criada especificamente para o objeto; (iv) teste de uma teoria baseada nas regularidades verificadas; e (v) o caso crucial, que reforça ou refuta a teoria testada. Entende-se que a contribuição desse caso é do tipo (ii), pois é mais que a descrição do objeto: também descreve suas regularidades conforme observadas por mais de um observador. Também entende-se que seja do tipo descritivo, já que é mais que um primeiro contato com o objeto, mas não chega a investigar relações de causalidade. 0 caso é qualitativo, porque trata com impressões, julgamentos, valores, representações, hábitos, atitudes e opiniões de operadores, sistematizados e organizados por pesquisadores.

As técnicas de pesquisa foram: análise de documentos, entrevistas semiestruturadas e grupos focados. Primeiramente, foi feita análise de documentos existentes para entendimento e contextualização do objeto. Após, foram conduzidas duas rodadas de sessões de grupos focados. Na primeira, pesquisadores e gestores estudaram o objeto e identificaram e estruturaram os principais fatores que influenciaram ou criaram condições de emergência ou insegurança. Resultou questionário estruturado incluindo os fatores. $\mathrm{Na}$ segunda, os pesquisadores reuniram quatro operadores líderes de painel de turnos diferentes e conduziram sessões guiadas pelo questionário. Os resultados das sessões serviram como elemento de análise do objeto.

\subsection{Objeto}

A instalação é equipada com duas caldeiras aquotubulares, que queimam óleo, gás, carvão, cera e borra oleosa, e uma caldeira aquotubular que queima óleo e gás. Cada caldeira produz $280 \mathrm{t} / \mathrm{h}$ de vapor à pressão de $113,0 \mathrm{kgf.} \mathrm{cm}^{-2}$ e temperatura de $525{ }^{\circ} \mathrm{C}$. 0 vapor de super (VS) gerado nas caldeiras é enviado a dois coletores de vapor de 113,0 kgf.cm-2.

A operação da planta é controlada por operadores líderes de turno, que trabalham em painéis de comando localizados em sala de controle e são apoiados por operadores de campo. A sala é ampla, equipada com condicionamento de ar, local para reunião e instalaç̧ões sanitárias e para refeições próprias. 0 controle é por SDCD (Sistema Digital de Controle Distribuído), e a interface com os operadores é por software supervisório - a principal interface homem-máquina são quatro terminais de vídeo de 22 polegadas, de muito boa resolução. Há a possibilidade de retirada de relatórios da situação em papel. As cadeiras e mesas de controle são ergonômicas e confortáveis.

Foi a partir de um acidente com 58 mortes em 1905, em Massachusetts, que a sociedade despertou para a necessidade de procedimentos para construção, manutenção e operação das caldeiras. Caldeiras implicam diversos tipos de risco: incêndios, explosões, choques elétricos etc. Na maioria dos casos, as consequências são 
catastróficas, em virtude da quantidade de energia liberada instantaneamente. Durante uma ocorrência anormal, pode haver aumento de emissões de $\mathrm{NO}_{x}$, $\mathrm{SO}_{2}$, CO e material particulado e descarga de vapor para a atmosfera (CROW; LOUVAR, 1990).

Emergências em gerador de vapor podem causar danos em pessoas, meio ambiente, material e na imagem da empresa. Geralmente, os custos de correção do problema são maiores que os de prevenção. Um grande acidente fica marcado, possivelmente para sempre, diante da sociedade, tal como em Bopal, na Índia, em Seveso, na ltália, e em Three Mile-lsland, nos EUA (KLETZ, 1993). Do ponto de vista econômico, uma emergência no gerador de vapor pode trazer prejuízos significativos: (i) perda de produção e impacto em prazos de entrega; (ii) multas referentes a quebras de contratos com clientes e a órgãos de controle ambiental; (iii) gastos com pessoal e materiais de manutenção em decorrência de danos em equipamentos; e (iv) prejuizos intangiveis, tais como imagem diante da sociedade.

\subsection{Método de trabalho}

A primeira rodada de sessões de grupo focado foi feita com a mediação de dois pesquisadores com atuação acadêmica e praticante e reuniu cinco gestores praticantes das áreas de produção, manutenção e segurança da instalação, com formação em engenharia. 0 fio condutor das sessões foi um levantamento dos eventos registrados desde 1997. Foram selecionadas situações anormais de riscos ou danos pessoais, materiais ou ambientais, contemplando aspectos operacionais e comportamentais. Foram considerados relatórios de incidentes, nos quais foram percebidas e registradas situações eventuais, não documentadas em procedimentos e que não tiveram decorrência prática, mas poderiam ter tido (por exemplo, tampa de válvula de segurança montada errada). Também foram analisados quase-acidentes, nos quais houve alguma ação ou situação concreta de risco, mas que não se materializou em dano (por exemplo, operador que tropeçou em escada e não havia corrimão para sustentação), e acidentes. Nestes, uma situação de risco se materializou e provocou dano (por exemplo, vazamento de óleo combustível, por erro de manutenção em tubulação). A condução do grupo focado foi como em Ribeiro e Newmann (2003) e valeu-se de perguntas colocadas em ordem crescente de profundidade. Os dois pesquisadores, por análise de discurso das respostas, extraíram os principais pontos presentes nas situações de risco. Como resultado, surgiu uma estrutura de fatores presentes nas anormalidades, que depois foi transformada em questionário estruturado. Cada ponto relevante surgido da análise de discurso originou uma questão. Os cinco praticantes criticaram e eventualmente corrigiram a estrutura e o questionário.

A seguir, realizaram-se sessões com quatro operadores líderes de equipe da Unidade de Produção de Vapor, representando quatro dos cinco grupos de turno existentes. Os quatro são operadores seniores de painel e possuem liderança sobre a equipe de campo, que inclui operadores menos experimentados. Alguns membros da equipe de campo podem ter menos de cinco anos de experiência. É dos operadores líderes a responsabilidade de tomar decisões em situações de emergência. Os entrevistados têm em média 20 anos de trabalho na empresa e trabalham em regime de turno (três turnos de oito horas e regime de revezamento de acordo com calendário específico). As entrevistas foram individuais. A participação foi voluntária. As sessões se realizaram no local de trabalho, em mesa de reuniões existente na casa de controle do gerador de vapor, em distância que permite visualizar as telas do sistema supervisório da instalação.

\subsection{Resultados}

0 questionário estruturado que resultou das sessões de grupo focado aparece no Quadro 1. As perguntas foram agrupadas por assunto: confiabilidade humana; alarmes, registros e capacitação de operadores.

Iniciou-se pela confiabilidade humana.

A primeira pergunta foi: Já ocorreu alguma condição na planta que não estava abordada em procedimentos ou o procedimento existente não era totalmente aplicável? Pelas respostas, em diversos momentos, a condição operacional da planta não estava contemplada no procedimento de parada de emergência disponível ou o procedimento não poderia ser adotado na condição operacional apresentada. Nem todas as ações necessárias estavam definidas. Com o tempo, os procedimentos foram alterados incluindo atividades e situações possíveis de acontecer durante uma emergência. 0 grupo considerou que um bom procedimento é aquele que antecipa a maioria das perturbações possíveis e indica para os operadores os ajustes operacionais necessários. Foi constatado que os operadores entendem os procedimentos como passíveis de erros e sujeitos a alterações contínuas, o que reduz a confiança no procedimento, induzindo ações intempestivas e abrindo espaço para o erro humano. Os operadores entendem que, para aumentar a 
Quadro 1. Questionário usado nos grupos focados.

\begin{tabular}{|c|c|}
\hline Construto & Perguntas \\
\hline Confiabilidade humana & $\begin{array}{l}1 \text { - Já ocorreu alguma condição na planta que não estava abordada em procedimento ou o } \\
\text { procedimento existente não era totalmente aplicável? } \\
2 \text { - } 0 \text { que é feito se o procedimento de parada de emergência não é cumprido? } \\
3 \text { - A disposição dos procedimentos é de facil acesso? } \\
4 \text { - Se o procedimento de emergência for seguido, o resultado é satisfatório? } \\
5 \text { - Para o atendimento a uma emergência, qual é o efetivo necessário? } \\
6 \text { - Se a emergência ocorrer em turno, o atendimento fica comprometido pelo número de } \\
\text { operadores na área? }\end{array}$ \\
\hline Alarmes & $\begin{array}{l}7 \text { - Quando muitos alarmes sinalizam, você se sente pressionado ou estressado? } \\
8 \text { - Os alarmes auxiliam no atendimento à emergência? } \\
9 \text { - Em que momento eles são desligados? Você retiraria algum alarme de operação? }\end{array}$ \\
\hline Registros & $\begin{array}{l}10 \text { - Quais as informações registradas nos relatórios de ocorrência anormal e onde são } \\
\text { acessadas? } \\
11 \text { - Já ocorreu alguma condição na planta em que os instrumentos de painel sinalizaram algo } \\
\text { incorreto, fora da variação esperada ou deixaram de sinalizar algo importante que não foi } \\
\text { registrado? }\end{array}$ \\
\hline Capacitação de operadores & $\begin{array}{l}12 \text { - Como funciona a capacitação de novos operadores para o atendimento à emergência } \\
\text { operacional? Como é avaliado se o mesmo já está apto? } \\
13 \text { - Quem tem voz de comando em emergência? } \\
14 \text { - Que fatores mais comprometem a segurança operacional? } \\
15 \text { - É possivel praticar o atendimento de emergências operacionais? }\end{array}$ \\
\hline
\end{tabular}

confiabilidade do sistema, é necessário que as regras sejam explícitas e que todas as situações estejam abordadas em procedimentos claros e objetivos, não permitindo interpretações dúbias e prevenindo enganos no nível de regra.

A próxima pergunta foi: $O$ que é feito se $o$ procedimento de parada de emergência não é cumprido? Os operadores relataram que já houve situações em que os procedimentos não foram cumpridos. Durante a emergência, não é sempre que se consegue identificar se o procedimento foi seguido rigorosamente ou não. Quando foi possível constatar o não atendimento do procedimento, não houve responsabilização ou ação corretiva nem discussão sobre as regras que deveriam ser obedecidas, e não foram. 0 fato de não ser possível ao operador de painel conferir se sua orientação foi seguida pelos operadores de campo e de não haver forma de responsabilização, caso não seja, faz com que alguns operadores de campo ajam da forma que lhes for mais conveniente, não observando pontos de vista mais abrangentes. Essa postura está se reduzindo, pois os operadores têm sido treinados para avaliar a situação como um todo e não pensar somente na sua parte do processo.

A próxima pergunta foi: $A$ disposição dos procedimentos éde fácil acesso? Todos responderam afirmativamente.

A pergunta seguinte: Se o procedimento de emergência for seguido, o resultado é satisfatório? Os operadores responderam que emergências são diferentes umas das outras. Nem sempre foi possível utilizar os procedimentos disponíveis, pois não eram adequados à situação. Procedimentos foram sendo alterados a cada emergência atendida. Após diversas alterações, identificou-se a necessidade da criação de um grupo de especialistas para reavaliação periódica. Como exemplo, um dado procedimento exige efetivo mínimo de nove operadores, e em certa passagem admite que operem oito: ou é aceitável operar com oito operadores e o procedimento não é fidedigno, ou a organização assumiu risco ao não escalar o efetivo necessário. Foram relatadas situações em que procedimentos abrangentes e genéricos demais deram margem a que fossem criados atalhos, tornando partes dos procedimentos incompletas ou incoerentes. Os operadores acham que as regras devem ser explicitas e todas as situações abordadas de forma simples. Acreditam ser capazes de antecipar a maioria das perturbações que possam ocorrer nas atividades e indicar os ajustes necessários, não permitindo interpretações dúbias. Também acham que os procedimentos devem ser confeccionados por operadores que trabalham diretamente na atividade.

A próxima pergunta foi: Para o atendimento a uma emergência, qual é o efetivo envolvido? Os operadores declararam que o número atual é de quatro operadores (dois no campo, dois no painel). Também declararam que essa quantidade não é suficiente para operação segura. Considerando a renovação do quadro, com operadores inexperientes, não tem sido possível antecipar perturbações, pois estes não tiveram tempo suficiente para desenvolver a capacidade de detecção e interpretação de sinais que os operadores mais experientes possuem. 
A última pergunta do bloco foi: Se a emergência ocorrer em turno, o atendimento fica comprometido pelo número de operadores que está na área? Segundo os entrevistados, há comprometimento. Seria necessário que pelo menos um dos operadores de campo tivesse cinco anos de experiência para se ter certeza de que as instruções de campo são bem interpretadas. Foi considerada aleatoriedade o fato de que as últimas emergências aconteceram em horário em que havia mais operadores habilitados.

Das discussões com o grupo, depreendeu-se que os líderes de equipe entrevistados, por serem mais experientes, dominam maior repertório de estratégias de enfrentamento de problemas e são capazes de antecipar e solucionar maior número de situações não previstas que os colegas de campo, menos experimentados. Estes tendem a fazer apenas o trabalho normal, com limitado repertório de capacidades. Devido ao dimensionamento reduzido da equipe, têm sido raras as oportunidades de trocarem informações com os operadores líderes sobre manobras mais críticas ou receberem realimentação sobre suas ações. Por fim, e mais grave, segundo os pesquisadores, é a aparente inadequação de alguns dos procedimentos descritos que estão em vigência na instalação e que são seguidos pelos operadores de campo.

Passou-se ao efeito dos alarmes nas decisões dos operadores.

A primeira pergunta foi: Quando muitos alarmes sinalizam, você se sente pressionado ou estressado? Após iniciada a emergência, muitos alarmes disparam ao mesmo tempo. Nessa hora, as telas de alarmes provocam erros do tipo countersigns e nonsigns: informação contraditória ou confusa, que pode disparar a regra errada. Os operadores relataram que a maior parte dos alarmes é sem sentido, oriunda de subsistemas que não fazem parte da solução do problema e os confundem e distraem, tornando o diagnóstico mais difícil e atrapalhando a priorização de informações. Nos primeiros segundos da emergência, há grande perturbação, dificultando a concentração, aumentando o nível de estresse e prejudicando o desempenho dos operadores que se sentem pressionados com os alarmes acionados. Para tornar a operação mais amigável, o operador desliga todos os alarmes possíveis no momento.

A próxima pergunta foi: Os alarmes auxiliam no atendimento da emergência? Os operadores reafirmaram que, algumas vezes, os alarmes que entram nesse momento provocam confusão ou erro, pois requerem do sistema supervisório uma tela de alarme e esta abre uma janela que se impõe sobre a tela de informação do processo. Nesse momento, o operador precisa utilizar diversas microjanelas de informação para completar sua tarefa, e a tela de alarmes atrapalha. Foi relatado que os alarmes auxiliam durante uma operação normal de planta mas, no momento da emergência, chamar o quadro de alarmes e decidir quais desligar pode atrapalhar.

A última pergunta do bloco foi: Em que momento eles são desligados? Você retiraria algum alarme de operação? Os operadores confirmaram a necessidade de um gerenciador de alarmes para todo o processo, mas principalmente após desligamentos de emergência pois, ao entrar em modo de emergência, devem ignorar as telas de alarmes: seguir estritamente o procedimento, e o som dos mesmos passa a ser uma perturbação.

Das discussões com o grupo, depreendeu-se que existem erros importantes de engenharia na configuração de alarmes do sistema supervisório. As funções de alarmes estão desatualizadas para a instalação e têm atrapalhado operadores em situações de emergência. Urge uma revisão sobre a função.

Passou-se ao bloco dos registros.

A primeira pergunta foi: Quais as informações registradas nos relatórios de ocorrências anormais e onde são acessadas? Os operadores declararam que somente informações de atendimento a equipamentos e instrumentos são registradas de forma padronizada e ordenada. Informações de atendimento operacional, tais como cumprimento de procedimentos de atendimento e sua aplicabilidade, número adequado de operadores, compreensão dos sinais de alarme, entre outras, não são registradas de forma padronizada. Resultam tratadas informalmente junto aos colegas que vivenciaram a situação, não sendo possível utilizar os relatórios de ocorrência para ações corretivas de comportamentos humanos. Os operadores declararam que os registros das ocorrências devem ser realizados de forma que todos os aspectos sejam abordados, mantendo o histórico de não conformidades para utilização em treinamentos posteriores. Como operadores que entram não vivenciaram os eventos do turno anterior, seus significados devem ser compartilhados no início do turno. Também deveria haver mais padronização no preenchimento das informações para histórico e na análise das circunstâncias por detrás das ocorrências.

A última pergunta do bloco foi: Já ocorreu alguma condição na planta em que os instrumentos de painel sinalizaram algo incorreto, fora da variação esperada, ou deixaram de sinalizar algo importante que não foi registrado? Os operadores declararam que a automação trouxe benefícios econômicos, reduzindo o efetivo envolvido. Aumentou também 
a flexibilidade operacional, permitindo que a planta trabalhasse mais próxima dos seus limites, durante mais tempo e com maior precisão. A implantação de alarmes automatizados trouxe melhorias na segurança com a redução da carga mental de trabalho. Porém, com o avanço da automação, surgiu a necessidade de integração de informações, hoje incompleta.

Depreendeu-se que os operadores não entendem completamente o controle computacional, gerando alguma perda da consciência situacional e da capacidade de operar manualmente a planta. Foram relatadas situações em que a manobra de campo realizada deveria ter acionado outros equipamentos, o que não ocorreu. E outras circunstâncias em que instrumentos importantes não atuaram, e a não conformidade foi detectada em campo por operador experiente que observou o comportamento do equipamento e constatou que ele não estava funcionando normalmente. Urge revisão do sistema lógico.

Passou-se então ao último bloco, capacitação de operadores.

A primeira pergunta foi: Como funciona a capacitação de novos operadores para o atendimento à emergência operacional? Como é avaliado se o mesmo já está apto? Segundo os entrevistados, a capacitação dos operadoresacontecepor treinamento em procedimento de atendimento a emergências. Há prova de procedimentos operacionais, e 25\% dessa prova tratam de atendimento desse tipo. Somente se adquire experiência necessária para 0 atendimento a emergências participando delas. Apesar de o nível técnico dos novos operadores ser considerado bom, falta-lhes vivência de campo. Em muitas situações novas, quando não podem contar com procedimentos escritos, operadores mudam o nível de controle cognitivo e passam a trabalhar no nível de conhecimento. Como consequência, a ação dos operadores passa a ser decisiva para a segurança da planta, recuperando o sistema técnico ou agravando a situação. Pelas respostas, foi possível observar que está presente na cultura da instalação que novos operadores aprendem com erros vivenciados, e consequentemente as instalações ficam sujeitas às consequências de decisões errôneas. Com a recente renovação de operadores, a probabilidade de deslizes e lapsos é maior, por isso é importante desenvolver métodos para a detecção. Deve haver treinamento permanente para operadores, segundo as diferentes funções e atribuições. Os treinamentos devem incluir procedimentos operacionais e eventuais modificações nas instalações e na tecnologia de processo.
A próxima pergunta foi: Quem tem $\mathrm{voz}$ de comando em emergência? Segundo os operadores, é clara a hierarquia de responsabilidades. 0 operador líder de turno é responsável por decisões sobre manobras operacionais em emergência. A decisão é tomada a partir da troca de informações entre o líder e a equipe de trabalho. Os operadores consideraram importante que, em manobras arriscadas ou realizadas em momentos críticos, seja respeitada a autoridade do líder e evitadas ações automáticas sem confirmação dele. Muitas vezes, ações fora do procedimento podem dar certo em determinado momento e serem reconhecidas como adequadas. Porém, pelo conceito de confiabilidade humana, esse tipo de situação deve ser analisada probabilisticamente, projetando as perdas que poderiam ter ocorrido.

A pergunta seguinte foi: Que fatores mais comprometem a segurança operacional?Segundo os operadores, são muitos os fatores que comprometem a segurança operacional, dentre eles: número reduzido de pessoas para atender a planta, excesso de confiança de operadores, que muitas vezes não seguem orientações, equipamentos obsoletos, apesar de serem bem conservados, pouco tempo de treinamento e falta de experiência de novatos, que ainda não têm vivência operacional para interpretar os sinais e condições da planta.

A última pergunta do bloco e da pesquisa foi: É possivel praticar o atendimento de emergências operacionais? Os operadores informaram que, com a estrutura existente, não é possível realizar simulados para manobras operacionais. Os operadores reconhecem a importância de treinar permanentementee avaliar as condições ergonômicas e fatores humanos da operação. Todos aceitariam passar por baterias de simuladores operacionais, submetendo-se a ter seu desempenho avaliado em cenários de acidentes simulados e operação normal, bem como validar novos procedimentos de operação. Os operadores propuseram laboratórios de interação homem-sistema, com instalação simulada que considera aspectos ergonômicos e fatores humanos que ocorrem na interação entre operadores, subsistemas e interfaces computadorizadas.

Da discussão com o grupo, depreendeu-se que a instalação está sujeita a modificações com o objetivo de melhorar a operacionalidade e a segurança, incorporar novas tecnologias e aumentar a eficiência de processos. Assim, considerando a complexidade do processo industrial e a manipulação de substâncias químicas perigosas, é importante a criação de um sistema gerencial que assegure que os riscos decorrentes das alterações possam ser identificados, avaliados e gerenciados previamente. 
Também percebeu-se que procedimentos não são capazes de interferir nas ações pessoais ou dar aos novatos a vivência necessária para antecipar os acontecimentos, por isso ações tomadas por pessoas sem histórico têm maior probabilidade de erro. Os operadores não têm dúvida sobre quem tem a voz de comando em emergência. Essa postura aumenta a confiabilidade humana, pois a tomada de decisão é prerrogativa do líder, que é operador experiente, com maior probabilidade de diagnosticar corretamente o cenário e atender a ocorrência no tempo correto. Também foram considerados oportunos exercícios simulados, com o objetivo de preparar operadores para situações potenciais de risco.

\section{Conclusões}

0 objetivo principal deste artigo foi apresentar uma análise de fatores que estiveram presentes e tiveram influência em situações de emergência observadas no gerador de vapor de uma planta petroquímica. Os objetivos secundários foram: (i) entender e contextualizar a situação do gerador estudado; (ii) estruturar as condições em que foram observadas situações de emergência no gerador; (iii) entender como essas condições afetam a confiabilidade da operação, principalmente a confiabilidade humana; e (iv) propor linhas de ação para aumentar a segurança da operação. 0 método foi o estudo de caso descritivo, com procedimento de pesquisa qualitativo. A principal técnica de pesquisa foi o grupo focado com operadores experientes, guiado por questionário estruturado.

0 questionário foi estruturado em quatro blocos: confiabilidade humana, alarmes, registros e capacitação. Das discussões com os operadores, foi possível extrair quatro linhas de ação para tornar mais segura a operação. A conclusão foi obtida por análise do discurso dos entrevistados.

Do primeiro bloco, depreendeu-se que a operação depende de operadores experientes e de procedimentos confiáveis. Também ficou clara a posição dos operadores de que há falta de contingente para tratar de situações de emergência. Como há renovação da equipe, conclui-se que é necessário diminuir a dependência da operação desses operadores. Os membros do grupo apontaram como necessidade a aceleração do treinamento dos novatos e que os procedimentos existentes devem ser revisados e atualizados permanentemente, em esforço contínuo da equipe de engenharia. Os pesquisadores incluíram uma política de longo prazo de redução de dependência de intervenções humanas, primeiro por simplificação e racionalização de procedimentos, depois por automação do que for possivel, e por fim de documentação das práticas consolidadas.

Do segundo bloco de discussão, depreendeu-se que existem erros importantes na configuração de alarmes do sistema supervisório. Os operadores sugeriram simplificação nas lógicas de alarme. Os pesquisadores acrescentaram revisar a funcionalidade de todos os alarmes, ou seja, para o que foi concebido e qual a utilidade atual deles.

Do terceiro bloco de discussão, depreendeu-seque os registros históricos não são tão completos quanto poderiam e deveriam ser. Também detectou-se que os operadores não compreendem completamente o controle computacional, gerando alguma perda de capacidade de operar manualmente a planta. A sugestão dos pesquisadores foi similar à anterior: simplificar alguns procedimentos, racionalizar algumas lógicas de comando e depois automatizar, diminuindo a carga lógica e estratégica exigida dos operadores de painel. Também sugeriram modificar o método de busca de informações históricas no sistema de informação, empregando técnicas de bancos de dados, tais como palavras-chave, queries e estatísticas de desempenho, hoje inexistentes, e revisão de lógicas de comando.

Do último bloco de discussão, percebeu-se que melhorias a que toda instalação industrial está sujeita podem desencadear situações de risco, pois os operadores relataram dificuldades para se adaptar rapidamente a tais alterações. Dado que modificações melhoradoras podem e devem acontecer, os operadores sugeriram, e os pesquisadores apoiaram, a criação de laboratórios simulados, nos quais os procedimentos com as novas mudanças seriam desenvolvidos e testados. Laboratório de simulação é uma estação de trabalho simulada, instalada na casa de comando do gerador, em tudo igual às reais, porém ligadas a softwares de simulação de operação. Exercícios simulados podem auxiliar no desenvolvimento da memória de trabalho dos operadores novos e reforçam as práticas corretas para os veteranos. Tal prática também contribuiria com o tema discutido no primeiro bloco.

Em síntese, como resultado de pesquisa, emergiram quatro linhas de ação possíveis para aumentar a confiabilidade humana na operação: (i) simplificar, racionalizare automatizar procedimentos, e depois reescrevê-los, mantendo a partir de então uma sistemática permanente de manutenção de procedimentos; (ii) reprojeto do sistema de alarmes; (iii) reprojeto do sistema de informações históricas e de algumas lógicas; e (iv) instalação de laboratório de simulação operacional para depuração de lógicas e treinamento de novatos. 
A pesquisa adotou procedimento puramente qualitativo. Como continuidade, sugere-se sua replicação, porém segundo procedimento quantitativo. Ao questionário seria acrescida uma escala de Likert de sete pontos [discordo totalmente... concordo totalmente], e este seria preenchido por todos os operadores que trabalham na instalação, o que totaliza quarenta indivíduos. Nas respostas, seriam aplicadas técnicas de estatística multivariada, tais como o alfa de Crombach, para análise de confiabilidade das respostas, análise fatorial, para eventual simplificação do questionário, análise de correlação entre os construtos investigados e eventualmente análise de regressão múltipla com fatores independentes, tais como tempo de experiência, tempo de treinamento, rotatividade dentro de equipes de turno, integração dentro da equipe etc.

\section{Referências}

ALMEIDA, 1. Gestão Cognitiva da Atividade. Revista Brasileira de Medicina do Trabalho, v. 2, n. 4, p. 1-12, 2004.

ALMEIDA, 1. Abordagem sistêmica de acidentes e sistemas de gestão de saúde e segurança do trabalho. INTERFACEHS - Revista de Gestão Integrada em Saúde do Trabalho e Meio Ambiente, v. 1, n. 2, p. 1-27, 2006.

ALMEIDA Jr., J. Segurança em sistemas críticos e em sistemas de informação: um estudo comparativo. 2003. $191 \mathrm{f}$. Tese (Livre Docência) - Universidade de São Paulo - USP, São Paulo, 2003.

AMALBERTI, R. The paradoxes of almost totally safe transportation systems. Safety Science, v. 37, n. 2-3, p. 109-126, 2001.

AMBROS, P. Avaliação da metodologia Atheana para sua utilização na análise da confiabilidade humana $\mathrm{em}$ usinas nucleares. 2005. 204 f. Dissertação (Mestrado em Engenharia Nuclear) - COPPE/Universidade Federal do Rio de Janeiro - UFRJ, Rio de Janeiro, 2005.

ASHBY, W. An introduction to cybernetics. London: Methuen Co., 1956.

BARANAUSKAS, M.; ROSSLER, F.; OLIVEIRA, O. Uma Abordagem Semiótica à Análise de Interfaces: um estudo de caso. In: WORKSHOP SOBRE FATORES HUMANOS EM SISTEMAS COMPUTACIONAIS, 1, 1998, Maringá, PR. Anais... São Paulo: 1HC, 1998. p. 1-10.

BEGOSSO, L. S. PERERE: Uma Ferramenta Apoiada por Arquiteturas Cognitivas para o Estudo da Confiabilidade Humana. 2005. 206 f. Tese (Doutorado em Engenharia Elétrica) - Universidade de São Paulo, São Paulo, 2005.

CACCIABUE, C. Fattori umani per la sicurezza sistemica: metodi di affidabilità umana per analisi di rischio. Milão: Riparto Ingegneria Aerospaziale, 2008. (Cuaderni di lavoro, Politecnico di Milano).

CACCIABUE, C. A methodology of human factors analysis for systems engineering: theory and applications. IEEE Transactions on Systems, Man and Cybernetics - Part A: Systems and Human, v. 27, n. 3, p. 325-339, 1997.
CAlARGE, F.; DAVANSO, J. Conceito de Dispositivos à Prova de Erros Utilizados na Meta do Zero Defeito em Processos de Manufatura. Revista de Ciência \& Tecnologia, v. 11, n. 21, p. 7-18, 2003.

CARVALHO, P.; VIDAL, M.; CARVALHO, E. Análise de micro incidentes na operação de usinas nucleares: estudo de caso sobre o uso de procediemntos em organizações que lidam com tecnologias perigosas. Gestão \& Produção, v. 12, n. 2, p. 219-237, 2005.

CROW, D.; LOUVAR, J. Chemical Process Safety: Fundamentals with Applications. New Jersey: Prentice Hall, 1990.

DUARTE, M. Riscos Industriais. Etapas para a investigação e a prevenção de acidente. Rio de Janeiro: FUNENSEG, 2002.

DROGUETT, E.; MENÊZES, R. Análise da confiabilidade humana via redes bayesianas: uma aplicação à manutenção de linhas de transmissão. Produção, v. 17, n. 1, p. 162-185, 2007.

FILGUEIRAS, L. APIS: Método para Análise e Projeto de Interfaces Homem-Computador visando a confiabilidade humana. 1996. 259 f. Tese (Doutorado em Engenharia Elétrica) Universidade de São Paulo - USP, São Paulo, 1996.

FISCHER, D.; GUIMARÃES, L.; SCHAEFFER, C. Percepção de Risco e Perigo: Um Estudo Qualitativo no Setor de Energia Elétrica. In: ENCONTRO NACIONAL DE ENGENHARIA DA PRODUÇÃO (ENEGEP), 22, 2002, Curitiba, PR. Anais... Rio de Janeiro, RJ: ABEPRO, 2002. p. 1-8.

ORGANIZAÇÃO INTERNACIONAL DO TRABALHO - OIT. Prevenção de acidentes industriais maiores. Rio de Janeiro: FUNDACENTRO, 2002. p. 122.

GANDRA, J.; RAMALHO, W.; GONÇALVES, C. Acidentes do Trabalho: Evoluindo do Modelo de Causalidade Centrada no Indivíduo para o Modelo de Cultura Organizacional. In: SEMINÁRIOS EM ADMINISTRAÇÃO, 7, 2004, São Paulo, SP. Anais... São Paulo: FEA-USP, 2004. p. 1-13.

GERTMAN, D. Representing cognitive activities and error in HRA tree. Reliability Engineering and Systems Safety, v. 39, n. 1, p. 25-34, 1993.

GUBER, N. Responsabilidade no projeto do produto: uma contribuição para a melhoria da segurança do produto industrial. 1998. 165 f. Dissertação (Mestrado em Engenharia de Produção e Sistemas) - Universidade Federal de Santa Catarina - UFSC, Florianópolis, 1998.

KANTOWITZ, B.; SORKIN, R. Human factors: understanding people-system relationships. New York: John Wiley \& Sons lnc., 1983.

KIRWAN, B. Human error identification in human reliability assessment. Part 1: Overview of approaches. Applied Ergonomics, v. 23, n. 5, p. 299-318, 1992.

HALLBERT, B. et al. The use of empirical data sources in HRA. Reliability Engineering \&t System Safety, v. 83, n. 2, p. 139-143, 2004.

HOLLNAGEL, E. Human reliability analysis: Context and control. New Jersey: Academic Press, 1993.

KLETZ, T. O que houve de errado? Casos de desastres em indústrias químicas, petroquímicas e refinarias. São Paulo: Makron Books, 1993.

LEE, K.; TILLMAN, F.; HIGGINS, J. A Literature Survey of the Human Reliability Component in a Man-Machine System. IEEE Transactions on Reliability, v. 37, n. 1, p. 24-34, 1988. 
LORENZO, D. Um guia do gerente para reduzir erros humanos: melhorando o desempenho humano nos processos industriais. [S.I]: EQE International Inc., 2001.

MONTMOLLIN, M. A ergonomia. Lisboa: Instituto Piaget, 1990.

MOSLEH, A.; CHANG, Y. H. Model-based human reliability analysis: prospects and requirements. Reliability Engineering and System Safety, v. 83, n. 1, p. 241-253, 2004.

NORMAN, D. Design Rules Based on Analyses of Human Error. ACM Transactions on Mathematical Software, v. 26, n. 4 , p. 254-258, 1983.

NORMAN, D.; DRAPER, S. User Centered System Design in New Perspectives on Human-Computer Interaction. Hillsdale: Lawrence Erlbaum Associates, 1986.

PASSOS, J. Riscos e Perdas Patrimoniais no Contexto Organizacional - Uma Abordagem Sob o Enfoque Sociotécnico. Revista da CEPPG, v. 7, n. 1, p. 88-99, 2002.

PERROW, C. Organizing to reduce the vulnerabilities of complexity. Journal of Contingencies and Crisis Management, v. 7, n. 3, p. 150-5, 1999.

PULAT, M. Fundamentals of Industrial Ergonomics. New York: Prentice Hall, 1992.

RASMUSSEN, J. Skills, Rules, and Knowledge; Signals, Signs, and Symbols, and other distinctions in human performance models. IEEE: Transactions on Systems, Man, and Cybernetics, v. 13, n. 3, p. 257-266, 1983.

REASON, J. Human error. Cambridge: Cambridge University Press, 1990.

REASON, J. Managing the risks of organizacional accidents. London, UK: Ashgate Publishing, 1997.

RIBEIRO, J.; NEWMANN, C. Planejamento e condução de grupos focados. In: RIBEIRO, J. (Org.) Grupos focados: teoria e aplicações. Porto Alegre: FEENG-UFRGS-PPGEP, 2003.
ROESCH, S. Projetos de estágio do curso de administração: guia para pesquisa, projetos, estágios e trabalhos de conclusão de curso. São Paulo: Atlas, 2001.

SANDERS, M. Human factors in engineering and design. New York: McGraw-Hill, 1987.

SANDERS, J.; MORAY, N. Human error. cause, prediction, and reduction. Mahwah, NJ: Lawrence Erlbaum Associates Publishers, 1991.

SANTOS, A.; SISTO, F.; MARTINS, R. Estilos Cognitivos e Personalidade: Um Estudo Exploratório de Evidências de Validade. Revista de Psicologia da USF, v. 8, n. 1, p. 11-19, 2003.

SHARIT, J. Human error. In: SALVENDY, G. (Org.). Handbook of human factors and ergonomics. New York: Wiley, 2006.

SWAIN, A. Human reliability analysis: Need, status, trends and limitations. Reliability Engineering \& System Safety, v. 29, n. 3, p. 301-313, 1990.

SWAIN, A.; GUTTMANN, H. Handbook of Human Reliability Analysis with emphasis on Nuclear Power Plant Applications. Albuquerque: U.S. Nuclear Regulatory Commission, 1983.

SVEDUNG, 1.; RASMUSSEN, J. Graphic representation of accident scenarios: Mapping system structure and the causation of accidents. Safety Science, v. 40, n. 5 p. 397-417, 2002.

TEIXEIRA, D. et al. Ergonomia na concepção de interfaces gráficas de salas de controle avançadas de reatores nucleares. Gestão Industrial, v. 3, n. 2, p. 146-158, 2007.

WICKENS, C. Engineering Psychology and Human Performance. New York: Harper Collins, 1992.

YIN, R. Estudo de caso: planejamento e métodos. Porto Alegre: Bookman, 2001.

\title{
Qualitative analysis of influential issues in risky situations observed in the steam generator of a petrochemical facility
}

\begin{abstract}
This paper presents an analysis of influential factors in emergencies in the steam generator of a petrochemical facility. Secondly, the paper aims to understand and situate the generator; to structure the conditions observed in abnormal situations; to understand how these conditions influence safety; and to propose guidelines in order to enhance it. The case study research method was applied using qualitative procedures. The main research technique was the focus group with operators, based on a four-section structured questionnaire: human reliability, alarms, occurrences registers and training. The findings consist of four guideline recommendations to improve safety: rationalization and automation of procedures, redesign of alarms, redesign of the logging and information system and an operational simulator.
\end{abstract}

Keywords

Human error. Emergency situation. Human reliability. Man-machine interaction. 